\title{
Indian Engineering Education needs a Reboot
}

\author{
Claire Komives \\ Professor, Chemical \& Materials Engineering ENGR lab 109 \\ San Jose State University 1 Washington Sq. \\ San Jose, CA 95192-0082
}

Many opinions have been shared of late regarding the education of engineers in India. The usual list of criticisms includes outdated curricula (2017), poor preparation of college faculty, need for professional and critical thinking skills (Gupta 2019, Sanghi 2019), the need to reduce in theoretical content in favor of practical knowledge, and a lack of connection with industrial practitioners (Mahadevan 2019). The updating of the syllabus and incorporating active learning can help support students to develop both communication and critical thinking skills, as proven by engineering education research (Felder and Brent 2016), but this is only a bandage on a system that is not fixable without updating the policies at the national level. Additionally, there is no motivation from The Apex Body to utilize modern pedagogy as there is no measure for these practices in the accreditation process.

Although the number of students enrolled has declined rapidly in the past two years, the total enrollment in the 2016-2017 school year in BE/B. Tech was 7,87,127, (ETOnline 2018) of which less than $4 \%$ were attending IIT's or NIT's. Thus, the vast majority of engineering students in India attend private engineering colleges.

\section{Claire Komives}

Professor, Chemical \& Materials Engineering ENGR lab 109 San Jose State University 1 Washington Sq. San Jose, CA 95192-0082
A typical day at a quality private engineering college, one that enjoys full enrollment along with The Apex Body and NBA accreditation, in India begins around 9:30 am. Classes run Monday to Saturday (some have a half day on Saturdays), allowing students only Sundays for a break. Students attend seven 50 minute classes each day with a break for lunch and two 15 minute tea breaks, once in the morning and once in the afternoon. For students not living in the hostels, busses depart at $4: 30 \mathrm{pm}$. That adds up to more than 40 hours per week in classes listening to lectures for the most part. Study time? At night and on Sunday only. Students travelling by bus from a distance, of which there are many, have little if any study time at night.

\section{More is not always better}

Thanks to the incredible number of classes that need to be taught, faculty likewise spend at least 15 hours per week teaching classes and labs. For comparison, San Jose State University where I teach, has a 12 units per semester teaching load, amounting to 12 hours per week in the classroom (see Figure 1). Most university faculty in the US have a teaching load that is half that amount when they are not engaged in sponsored research.

Recently, the Apex Body reduced the required number of units for an engineering program from 180 to 160 . This was definitely a move in the right direction, but it is not far enough. Once again, for 


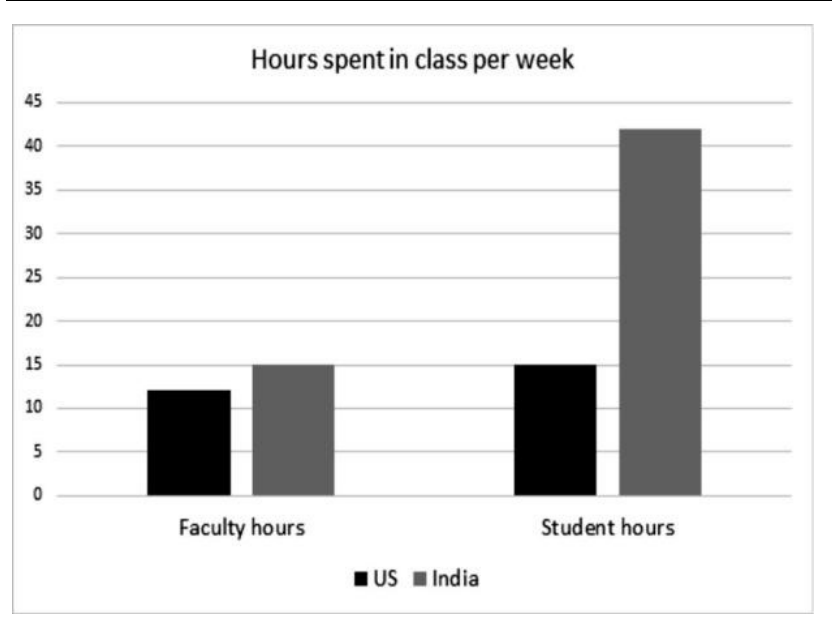

comparison, San Jose State university has only 120 required units. When you talk about incorporating projects into courses in India, so that students can acquire much needed teamwork skills, critical thinking skills, communication skills and industry relevant assignments, the question arises, "when can students work on them?" If a typical project takes 15 hours to complete, class time is insufficient. Students need more time to explore and create for practice of design thinking. Now the more forward thinking programs are adding one project course per semester, but where is the time for the students to work on them? I expect students in my classes at SJSU to spend at least 8 to 10 hours per week outside of class on homework, projects, and class preparation. That time does not exist in India.

In addition to the required number of course hours, the more is not always better mantra covers the policies enforced for NBA accreditation. The US accreditation body, ABET, had 11 student (program) outcomes up until this year. NBA joined the Washington Accord, in principle unifying the accreditation process with ABET who is also part of the Washington Accord. NBA had 12 outcomes. This year ABET reduced to seven outcomes, removing ones very difficult to assess and restructuring for simplicity. Meanwhile, NBA required the addition of at least three "program specific outcomes (PSO)" to their list. Per NBA, the PSO's must be distinct from the 12 PO's and should not be mapped to them. In my visits to over 10 private colleges and universities, I have yet to meet a PSO that I could not map to one or more the 12 NBA outcomes. The 12 outcomes cover everything, that is the nature of them. If that is not bad enough, the faculty must map each of their course outcomes every semester, including a level of knowledge and a level of mapping to the $\mathrm{PO}$ and
Program Educational Objective (PEO). This assessment is not only tedious, but since the course outcome performance is often tied to faculty merit reviews, naturally the students always meet the required acceptable level of performance, making the whole exercise quite futile.

Lessons from failure

Indian faculty in private engineering colleges struggle to motivate the students to learn. In the US, engineering students fail courses and must retake them. The desire to at least pass courses helps motivate students in the US to study. This exercise results in improvement of student learning and overall improvement of quality of graduates. It is very difficult for students to receive a failing grade in India because the colleges get dinged by the NBA (or worse, parents!) if there is a high rate of students taking more than four years to complete a degree. Since the students know they can't be failed, there is little accountability or motivation to excel, for the majority of the students. The top students everywhere strive to succeed, but the presence in the classroom of unmotivated students strains both students and faculty who want to learn and teach.

\section{How free are the autonomous colleges?}

Colleges that are not affiliated to government universities have some freedom to design their syllabi. Answerable only to a Board of Studies, in principle, faculty can write their own course outcomes, prepare their own examination questions and incorporate projects and active learning. Some colleges have transformed into Deemed Universities allowing additional freedoms. But even the autonomous colleges are still tied to NBA and The Apex Body. The student fees have been set by The Apex Body and the requirement to have one faculty per 15 students enrolled in a program adds up to zero profit. Apparently the 15 student number has recently been increased, not resulting in higher salaries for faculty but only additional workload for them. While the Indian leadership is pushing to reduce the cost of education by requiring more on-line courses, the best solution is to reduce the number of units. Right now, colleges could only accomplish reduced units by sacrificing accreditation. Without accreditation, colleges cannot compete for students, so they have no choice but to continue with the monumental amount of content that can only be taught superficially, since students have no time to study. 


\section{Remove the barriers to success}

In the US, the Board of Engineering Education (BEEd) composed of academics from various institutions in the US, industry practitioners, investors and government employees studied the current situation of Engineering Education in the US back in the 1990's. It was clear that changes had to be made because the students were graduating with a highly theoretical knowledge and failed to demonstrate professional and practical skills for employment (BEEd 1995). The committee sought a solution that could be prescriptive and implemented across the various colleges in the US. However, what they concluded was "there is no simple, universal prescription for dealing with complexity and constant change." Rather, there must be many responses, all individualized and tailored to local circumstances." As for implementation, the recommendation was as follows:

"To meet the challenges that the nation faces, each engineering college or school should enter a period of experimentation, monitored by self-assessment and feedback from industry, that is characterized by a willingness to change and by open, active communication across the engineering community."

This is happening in India in the IIT's, who are free from requiring any accreditation processes. Unfortunately, the IIT's cannot function as a model for private engineering colleges who serve a completely different population of stakeholders. There should be a separate Board of Principals for each type of college that can provide input for The Apex Body and NBA processes. As it is, private engineering colleges are accredited by NBA evaluators who are all from IIT or NIT's. There is a mismatch between the experience of the evaluators and the circumstances of the colleges.

\section{Bold proposition for India}

Imagine that colleges could be completely free to design their own curriculum, not tied to restrictions of fee structures or 160 units. I predict that the colleges that have solid leadership motivating faculty to improve their teaching by incorporating active learning and industry-relevant projects and assignments will turn out the much sought-after employable graduates, while the colleges glued to their past strategies will die out from lack of students. Allowing the free market to provide the motivation for success of colleges and graduates will drive the change that The Apex Body is aiming at, namely to close the colleges that are low quality. Through that process, colleges will be free to reduce memorizable content in favor of increasing learning experiences that include analyze, evaluate and design practice, in addition to quality professional skills. Higher revenue for colleges will enable higher salaries for faculty, resulting in an increase in quality of faculty. If faculty salaries could be increased, as well as the freedom (and time!) to do relevant research, the job would be more appealing. If instead of bean counting to determine quality benchmarks, The Apex Body and NBA served to mentor colleges to freely explore novel strategies, the engineering colleges could shape their own ecosystems to serve the highly diverse population of India. One size in education doesn't fit all, but helping foster success is always a positive endeavor.

\section{References}

[1](2017). "Why are Indian engineers not employable? IIT directors blame outdated curriculum and poor infra." INUTH May 17.

[2]BEEd (1995). "Engineering Education: Designing an Adaptive System." National Academies Press https://doi.org/10.17226/4907.

[3]ETOnline (2018). "India is in the middle of an engineering education crisis." The Ecomomic Times April 9.

[4]Felder, R. M. and R. Brent (2016). Teaching and Learning STEM: A Practical Guide, Wiley.

[5]Gupta, A. (2019). "Education Crisis: India Juggling With Engineering Education Issue, Need To Take Concrete Steps." Business World Education June.

[6]Mahadevan, N. (2019). "10 Skills to make Engineers More Employable in 2020." Entrepreneur Dec 26.

[7] Sanghi, D. (2019). "Engineering Grads Struggle for Jobs Not Because They Don't Know the Latest Stuff." The Wire 18 Nov 